\title{
Exploring the communication barriers in private commercial banks of Bangladesh
}

Sultana, Nahneen

Eastern University, Bangladesh (urmee97@yahoo.com)

Abdullah, Abu Md.

Eastern University, Bangladesh (abdullah.du@gmail.com)

Tabassum, Ayesha $\bigotimes$

Eastern University, Bangladesh (tabassum105@yahoo.com)

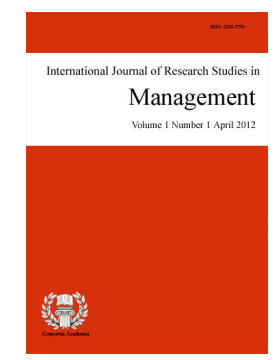

ISSN: $2243-7770$ Online ISSN: 2243-7789

OPEN ACCESS

\section{Abstract}

In Bangladesh, lots of private commercial banks are contributing for economic growth. The performance of the banks depends on a well-structured communication system. So by maintaining an effective communication system, the banks can gain competitive advantage. Thus the study aims to investigate the communication barriers that should be removed for effective communication in the private commercial banks of Bangladesh. A structured questionnaire survey based on 5-point Likert-scale was conducted on 165 full-time employees of private commercial banks. The sample includes 15 private commercial banks. The Principal Component Analysis reveals three types of communication barriers; personal barriers, job barriers, and organizational barriers. Among these barriers, personal barriers are the most significant barriers according to the respondents of the study. Personal barriers include lack of English knowledge, local tone, opposite sex and hot temper. The second most important barriers are job barriers that include technical words, personal life and job monotony. The third most important barriers are organizational barriers which include defective technology and internal politics.

Keywords: communication barriers; effective communication; private commercial banks; personal communication barrier; job communication barrier; organizational communication barrier 


\section{Exploring the communication barriers in private commercial banks of Bangladesh}

\section{Introduction}

Banks in Bangladesh now constitute the core of the country's organized financial system (Islam \& Husain, 2001). They not only mobilize the savings of people but also channel the resources towards different sectors of the economy (Islam \& Husain, 2001). Thus banks can play a vital role in fostering the economic and social condition of a country (Islam \& Husain, 2001). From the context of Bangladesh, financial sector reform in the country started in 1976 with privatization of the banks (Ahmad \& Khanal, 2007) and a rapid expansion of private banks has taken place from the mid 1990s till present (Rahman, Gurung, \& Saha, 2006). At present, there are 49 commercial banks of which 30 are private commercial banks. The banking sector employs a significant number of employees - more than 110,000 people (Ahmad \& Khanal, 2007). As success of the business depends on effective communication (Timm \& Jones, 1983), understanding the communication process of banks is crucial. Communication is the process of meaningful interaction among persons in an organization, resulting in meaning being perceived and understandings affected among such persons (Davar, 1979). Evidence of the importance of communication in business is found in numerous surveys of executives, recruiters and academicians (Lesikar, Flatley, Rentz, \& Pande, 2009). Within proper communication environment, message can be disrupted by a variety of communication barriers (Bovee, Thill, \& Chaturvedy, 2009). These barriers can distort the communication message and the entire communication process may fail, which can result in business failures as well. According to Helen and Alla (2011), efficient communication process can promote the positive image of the banks and the improvement of communication process depends on the elimination of communication barriers.

Communication plays the crucial role to success in any relationship undoubtedly. When there are barriers in the flow of communication in the organization within very short period of time it becomes the source of serious problems among employees. The situation goes out of control and employees find it extremely unpleasant and restraining to work on daily basis in such environment if this improper communication continues leading to the barriers go intense. As a result performance of employees decline sharply. Inadequate verbal and nonverbal exchange gradually leads to bitterness and thus a huge gap is created among employees and organizational authority.

Thus identifying the communication barriers is significant for ensuring effective communication in the service organizations, like banks, where the business processes heavily depend on communicating various types of information with the customers and stakeholders. As Grasso, Golen, and Burns (2005) mentioned that better understanding of communication barriers may help the business organizations to communicate more effectively and improve their ability to promote more effective communication throughout the organization. Recognizing the importance of an effective communication system, the current study aims at exploring the communication barriers in the private commercial banks of Bangladesh.

\section{Literature review}

The word 'communication' comes from the Latin word communis, which means common that indicates individuals strive for commonness of understanding the transmitted information (Gopal, 2004). Simply, communication may be understood as transfer of information, idea, opinion, attitude etc. from a sender to a receiver with a view to making it understandable to the latter (Khan \& Taher, 2012). Communication takes many forms; face-to-face conversations, informal meetings, e-mails, letters, memos, reports, and many others (Locker, 2000). In business organizations, three categories of communication can be found; these are internal-operational, external-operational and personal (Lesikar et al., 2009). According to van Riel (1995), different forms of organizational communication can be found, i.e. marketing communication, external or public relation 
Exploring the communication barriers in private commercial banks of Bangladesh

communication, internal communication, and many others. These communications usually take place through both formal and informal network in businesses (Lesikar et al., 2009).

Communication is vital to every business, even to a one-person business (Lesikar et al., 2009). Even no business can run and survive without communication (Ruler \& Lange, 2003). These authors have mentioned in their study that European scholars defined communication as a specialized management field. The importance of communication is also recognized by the Anglo-American scholars as well, as they treated communication as managerial and strategic (Ruler \& Lange, 2003). According to Lesikar et al. (2009), "communication enables human beings to work together". It happens because, effective communication can strength the connection between a business organization and all of its stakeholders, i.e. customers, suppliers, employees, shareholders, neighbors, the community and the nation (Bovee, Thill, \& Chaturvedi, 2008). That's why Sherblom (1998) treated business communication as a dynamic, bi-directional, multiply-influenced, and transformational translation process. By effective communication is meant the process of sending a message in such a way that the message received is close in meaning to the message intended (Khan \& Taher, 2012). But some meaning of the message can be lost or disrupted due to various communication barriers (Bovee, Thill, \& Chaturvedi, 2008).

Business communication usually face more barriers as the message is more complex, conditions are difficult, and at the same time psychological and social differences often separate the sender and the receiver (Gopal, 2004). Thus communication barriers can negatively affect the technical communication in an organization on which the success of a business depends (Sosa, Eppinger, Pich, McKendrick, \& Stout, 2002). Several scholars have identified different types of barriers. The barriers identified by Gopal (2004) are, physical, semantic, psychological and physiological, and other barriers (lack of common knowledge, unsolicited communication, over communication, politics, technical jargon).

Eisenhardt and Bourgeois (1988) also mentioned organizational politics as a barrier for successful communication. According to Braedyn (2010), both men and women struggle when communicating with opposite gender, which may create barrier for effective communication. Khan and Taher (2012) mentioned about four types of communication barriers; these are (a) sender related barriers, (b) receiver related barriers, (c) barriers related to both sender and receiver, and (d) situation related barriers. Bovee, Thill, and Chaturvedi (2008) considered noise and distractions, competing messages, filters, and channel breakdowns as some common communication barriers that could be found in business organizations. In terms of communication process sometimes barriers may arise due to the physical difference, culture differences, and different working conditions (Sosa et al., 2002). Grasso, Golen, and Burns (2005) reviewed a significant number of literature and found trust, credibility, size, physical distance, listening, and resistance to change as barriers to communication. According to Fisher (1981), the communication barriers are interrelated clusters, thus one barrier may create another barrier and increase the problems in communication process.

As a communicator, everyone should be aware about the communication barriers and try to avoid these barriers (Bovee, Thill, \& Chaturvedi, 2008) as effective communication can benefit the business in numerous ways, i.e. stronger decision making and faster problem solving, earlier warning of potential problems, increased productivity, stronger business relationships, more persuasive marketing messages, enhanced professional image, lower employee turnover, increased employee satisfaction, and better financial results and higher return for investors (Bovee, Thill, \& Chaturvedi, 2008). On the other hand, poor communication pay a price in wasted time, wasted effort and lost goodwill (Locker, 2000). Thus effective communication is always crucial for effective management, which helps the organizations to remain competitive in the business world (Grasso, Golen, \& Burns, 2005). Pearce, Figgins, and Golen (1988) stated, "to communicate effectively in business, you need to understand how barriers operate, why they interfere with communication, and how you can decrease their negative effect" (p. 33).

Apprehending the importance of communication, Ruler and Lange (2003) conducted a study on the barriers to communication management in the Netherlands. They looked for two suggestive factors as communication 
Sultana, N., Abdullah, A. M., \& Tabassum, A.

barrier; one is glass ceiling and the other one is encroachment. Though they found evidence of encroachment, glass ceiling was absent in terms of communication management. Al-Rawas and Easterbrook (1996) worked with several organizational and social issues, which have great influence on the effectiveness of communication and may turn as communication barriers. Grasso, Golen, and Burns (2005) recognized the attitudinal, perceptual, social, technical, competitive, and physical dimensions of communication barriers in their study.

\section{Research methodology}

\subsection{Development of measurement instrument}

On the basis of literature review and focus group interviews, a self-constructed nine-item structured questionnaire was prepared following 5-point Likert scale. Focus group interviews were conducted with 5 persons from 5 different banks of Bangladesh. Focus group interviews provide a broad frame for discussions, in which members express their opinions while discussing the issues (Kumar, 2009). Structured questionnaire was used as it is relatively convenient and inexpensive, and at the same time it can provide greater anonymity (Kumar, 2009). Respondents were asked to indicate to what extent they agree with the scale statements with 5-point scale ranging from strongly disagree (1) to strongly agree (5). The scale includes item, such as, "Internal politics create barrier to communication in my bank" and "Lack of English knowledge hinder my ability of communication in this bank". The last section was the demographic information of respondents namely; gender, job position, organization's name, and many others. To increase reliability and to assure appropriateness of the data collection instrument, the questionnaire was subject to a pilot test conducted with 10 private banking sector employees in Bangladesh.

\subsection{Data collection and sample}

Data were collected by visiting 15 private commercial banks through the questionnaire. In total 165 questionnaires were distributed among the employees of private commercial banks within September 2011 to December 2011. The banks were selected randomly, whereas the respondents were selected based on convenience. A total of 150 responses were used for the study. Rests were rejected due to the errors and incompleteness.

\subsection{Validity and reliability of instrument}

Hair, Black, Babin, Anderson, and Tatham (2007) defined the validity as "the degree to which a measure accurately represents what it is supposed to". Validity is concerned with how well the concept is defined by the measure(s). Siddiqi (2010) mentioned about three types of validity in his study: content validity, predictive validity, and construct validity. Duggirala, Rajendran, and Anantharaman (2008) defined the content validity as the assessment of the correspondence between the individual items and concept. Malhotra (2010) defines the content validity as face validity. This study addressed content validity through the review of literature and adapting instruments used in previous research.

Reliability differs from validity in that it relates not to what should be measured, but instead to how it is measured. Hair et al. (2007) defined reliability as the extents to which a variable or set of variables is consistent in what it is intended to measure. As the current study uses multiple items in all constructs, internal consistency method is applied. The Cronbach alpha with acceptable cut off point 0.70 demonstrates that all attributes are internally consistent (Fujun, Hutchinson, Li, \& Bai, 2007). The Cronbach alpha value for this study was 0.729, which meets the criteria of cut off point. Thus all the attributes of the study are reliable.

\subsection{Data analysis}

The responses of were analyzed with SPSS. The normality of the data was confirmed by illustration of the 
Exploring the communication barriers in private commercial banks of Bangladesh

Probability-Probability plot (P-P plot) of items. The central view and the diversity among the views of the respondents were observed in case of each item individually. The distribution pattern of all the components as a whole expressing all the basic features was observed along with Box-plot diagram. Then, Principal Component Analysis (PCA) was conducted to extract the communication barriers which influence the communication process in private commercial banks of Bangladesh.

\section{Results}

\subsection{Sample description}

The means, standard errors, and standard deviations were calculated for each questionnaire item, which is presented in Table 1. It is apparent that the communication barrier 'Opposite sex' occupies the highest mean value and 'Defective technology' occupies the lowest mean value.

\section{Table 1}

Description of sample

\begin{tabular}{lccc}
\hline \multicolumn{1}{c}{ Item scale } & Mean & Standard error & Standard deviation \\
\hline Lack of English knowledge & 2.57 & 0.102 & 1.244 \\
Local tone & 3.13 & 0.098 & 1.202 \\
Opposite sex & 3.83 & 0.085 & 1.045 \\
Hot temper & 2.50 & 0.087 & 1.067 \\
Defective technology & 2.31 & 0.072 & 0.883 \\
Technical words & 2.89 & 0.085 & 1.037 \\
Personal life & 3.23 & 0.085 & 1.045 \\
Job monotony & 2.62 & 0.079 & 0.967 \\
Internal politics & 2.41 & 0.083 & 1.011 \\
\hline
\end{tabular}

\subsection{Descriptive analysis}

The respondents were asked to rate the communication barriers' impact on their communication process. It was found that around half of the respondents (strongly agree 18\% and agree 42.67\%) think that lack of English can affect their communication in banks. Less than half of the respondents feel that their local tone in communication can create barriers in communication process. It is also evident that more than half (disagree $40 \%$ and strongly disagree $29.33 \%$ ) of the respondents think that they are not that much uncomfortable while communicating with opposite sex. Hot temper can create barrier to communication, as near about half of the respondents (agree 38\% and strongly agree 17.33\%) agreed with this issue. Very often defective technology can create barrier for communication in the banks, as more than half of the respondents agreed with this particular (see Table 2). Some employees (strongly agree $7.33 \%$ and agree 32.67\%) also face difficulty in terms of technical words used in banking sector. According to Table 2, sometimes personal life of the employees also has an influence on the communication process. Around half of the respondents (strongly agree $8 \%$ and agree $44.67 \%$ ) think that job monotony can be a barrier for effective communication. Similarly about half of the employees think that internal politics of the banks can create barriers for communication (see Table 2).

\subsection{Principle component analysis}

This study performed the PCA with Varimax rotation to extract the communication barriers which influence the communication process in private commercial banks of Bangladesh. PCA is used in those instances when the primary concern is to determine the minimum number of factors that would account for maximum variance in the data (Malhotra, 2010). In order to measure the appropriateness of the factor analysis, Kaiser-Meyer-Olkin 
Sultana, N., Abdullah, A. M., \& Tabassum, A.

(KMO) measure of sampling adequacy was examined. The value of KMO was 0.747 , which was an indication of sampling adequacy.

An examination of Eigenvalues confirms that three components were extracted. The extracted three components can explain as much as $56.22 \%$ of the total variation that is caused by the nine variables. The first component explains the most, about $22.83 \%$, second component explains $18.20 \%$, and third component explains $15.17 \%$ of the total variation. The remaining variance is explained by other components (see Table 3 ).

Table 2

Descriptive result of communication barriers

\begin{tabular}{llllcc}
\hline \multicolumn{1}{c}{ Communication Barriers } & $\begin{array}{c}\text { Strongly } \\
\text { Agree }(\%)\end{array}$ & Agree (\%) & Neutral (\%) & $\begin{array}{c}\text { Disagree } \\
(\%)\end{array}$ & $\begin{array}{c}\text { Strongly } \\
\text { Disagree (\%) }\end{array}$ \\
\hline Lack of English knowledge & 18.00 & 42.67 & 14.00 & 14.67 & 10.67 \\
Local tone & 4.67 & 37.33 & 12.67 & 30.67 & 14.67 \\
Opposite sex & 2.66 & 10.00 & 18.00 & 40.00 & 29.33 \\
Hot temper & 17.33 & 38.00 & 26.00 & 14.67 & 4.00 \\
Defective technology & 14.00 & 52.00 & 25.33 & 6.00 & 2.67 \\
Technical words & 7.33 & 32.67 & 28.00 & 27.33 & 4.67 \\
Personal life & 2.00 & 27.33 & 28.00 & 30.67 & 12.00 \\
Job monotony & 8.00 & 44.67 & 28.67 & 14.67 & 4.00 \\
Internal politics & 19.33 & 37.33 & 28.00 & 13.33 & 2.00 \\
\hline
\end{tabular}

Table 3

Total variance explained by PCA

\begin{tabular}{ccccccc}
\hline & \multicolumn{3}{c}{ Initial Eigenvalues } & \multicolumn{3}{c}{ Rotation Sums of Squared Loadings } \\
Component & Total & \% of Variance & Cumulative $\%$ & Total & \% of Variance Cumulative \% \\
\hline 1 & 3.105 & 31.048 & 31.048 & 2.284 & 22.836 & 22.836 \\
2 & 1.503 & 15.026 & 46.074 & 1.821 & 18.208 & 41.044 \\
3 & 1.015 & 10.145 & 56.220 & 1.518 & 15.175 & 56.220 \\
\hline
\end{tabular}

Note. Extraction method: Principal Component Analysis

The principle components are further rotated using Varimax with Kaiser Normalization algorithm. The result of the rotated component matrix is presented in the Table 4. Table 4 also shows the $h^{2}$ (communalities) of each variable. It varies from $45.1 \%$ to $77.8 \%$, suggesting the extracted factors are sufficient to account for most of the variations of variables existing in the data. The factor loading those are greater than 0.50 are considered and all the variables are loaded on the three components.

\subsubsection{Component 1}

It is evident from Table 4 that variables B1, B2, B3, and B4 have formed a group and explained $22.83 \%$ of the total variance. The accumulation of these variables under first component indicates the existence of latent relationship among them. The associated factor loading of the first element that means the variable 'Local tone' was 0.807 , which implied that it was highly correlated with the first component and could explain about $68.2 \%$ of the variance of communication barrier caused by this variable. Factor loading represents the correlations between the variables and the resulting component, and loadings greater than 0.5 collectively construct the component (Aaker \& George, 1990). The second variable was 'Hot temper' having factor loading 0.732, which could explain $57.6 \%$ of the variance caused by the variable. The third and forth variable of this component were 'Lack of English knowledge' and 'Opposite sex', having factor loading 0.647 and 0.621 respectively, which were able to explain $50.5 \%$ and $45.1 \%$ of variance caused by B3 and B1 variable (see Table 5). The communalities of the variables were satisfactory and thus ensured that the extracted components are well representatives of the 
original variables.

\section{Table 4}

Rotated component matrix

\begin{tabular}{|c|c|c|c|c|c|}
\hline \multirow{2}{*}{ No. } & \multirow{2}{*}{ Variables } & \multicolumn{3}{|c|}{ Component } & \multirow{2}{*}{$h^{2}$} \\
\hline & & 1 & 2 & 3 & \\
\hline $\mathrm{B} 1$ & Lack of English knowledge & 0.647 & & & 0.451 \\
\hline B2 & Local tone & 0.807 & & & 0.682 \\
\hline B3 & Opposite sex & 0.621 & & & 0.505 \\
\hline B4 & Hot temper & 0.732 & & & 0.576 \\
\hline B5 & Defective technology & & & 0.859 & 0.778 \\
\hline B6 & Technical words & & 0.705 & & 0.548 \\
\hline B7 & Personal life & & 0.799 & & 0.686 \\
\hline B8 & Job monotony & & 0.508 & & 0.453 \\
\hline B9 & Internal politics & & & 0.747 & 0.675 \\
\hline
\end{tabular}

\section{Table 5}

Component 1 - Personal barrier

\begin{tabular}{cccc}
\hline Variable Number & Name of the Variable & Factor Loading & $h^{2}$ \\
\hline B2 & Local tone & 0.807 & 0.682 \\
B4 & Hot temper & 0.732 & 0.576 \\
B1 & Lack of English knowledge & 0.647 & 0.505 \\
B3 & Opposite sex & 0.621 & 0.451 \\
\hline
\end{tabular}

\subsubsection{Component 2}

The second component formed with three variables B6, B7, and B8 that explained $18.20 \%$ of the total variance. According to Table 6, 'Personal life' had the highest factor loading that is 0.799 , which was able to explain about $68.6 \%$ of the variance of communication barrier caused by this variable. The second highest factor loading was 'Technical words' with 0.705 , which could explain $54.8 \%$ of the variance, and the third variable 'Job monotony' had factor loading 0.508 , which could explain $45.3 \%$ variance caused by this variable. All the communalities were satisfactory and representatives of original variables.

\section{Table 6}

Component 2 - Job barriers

\begin{tabular}{cccc}
\hline Variable Number & Name of the Variable & Factor Loading & $h^{2}$ \\
\hline B7 & Personal life & 0.799 & 0.686 \\
B6 & Technical words & 0.705 & 0.548 \\
B8 & Job monotony & 0.508 & 0.453 \\
\hline
\end{tabular}

\subsubsection{Component 3}

The third extracted component explained about $15.17 \%$ of the total variance and formed of two variables B5 and B9. 'Defective technology' had the highest factor loading within this component that is 0.859 , which could explain $77.8 \%$ of variance of communication barrier caused by the variable B5. Another variable under this component was 'Internal politics' with factor loading 0.747 , which could explain about $67.5 \%$ of the variance caused by the variable (see Table 7). 
Sultana, N., Abdullah, A. M., \& Tabassum, A.

Table 7

Component 3 - Organizational barriers

\begin{tabular}{cccc}
\hline Variable Number & Name of the Variable & Factor Loading & $h^{2}$ \\
\hline B5 & Defective technology & 0.859 & 0.778 \\
B9 & Internal politics & 0.747 & 0.675 \\
\hline
\end{tabular}

\section{Discussion}

The Principle Component Analysis classified the communication barriers in three components. The first component includes four variables which are classified as 'personal barrier'. These variables are B1 which is lack of English knowledge, B2 that is local tone, B3 which is opposite sex and B4 hot temper. These barriers among all the nine barriers relate to the employees' level of personal disqualification, as these factors are not influenced by any organizational policy or by someone else.

The second component includes three variables which are related with 'job barrier'. The factors are B6 technical words, B7 personal life and B8 job monotony. These three variables influence employees' communication arising from the job environment. Among these three, 'personal life' might seem irrelevant to be under this classification but the happenings in personal life influence the employee job performance. In case of family crisis, it is not easy for employees to concentrate with full dedication in the workplace and at the end of the day the tension appears as a barrier in performing job. For this reason this factor is included in this class of variables.

The third component is composed of two variables; those are B5 defective technology and B9 internal politics which straight indicates nothing but 'organizational barrier'. Employees can be skilled or not but if an organization is beset with defective technology and internal politics, employees face problems in communicating smoothly.

\section{Conclusion}

\subsection{Practical implications}

The study assesses the contribution of various components as barriers on communication of in terms of private commercial banks in Bangladesh. Different measures and analysis regarding the components can be explored from the study with a view to minimize the barriers. At the same time, the bank management can have more elaborated idea regarding the nature of communication problem in banking profession from this study. Therefore, the bank management may formulate module to ease the communication problem based on the findings of the current study. If these barriers to communication are left without consideration it can significantly reduce job performance and job satisfaction that is why a collaborative effort of both bank management and bank employees is crucial for fostering a jovial work environment in the private banks of Bangladesh. As a result, the bank employees will be able to get rid of their communication problems, which in turn will motivate them to put more effort in banking. Thus the current study can be a valuable source of empirical evidences for those practitioners who deal with the bank employees.

\subsection{Limitations and future research direction}

The results of this study need to be viewed and acknowledged in lights of its limitations. First, the sample size was considerably low. Moreover, only few banks are selected randomly. If the sample includes a significant proportionate of respondents to the total population then the study will be more reliable. To reduce the biases and errors in sample, the banks should be selected with more authentic statistical sampling technique, such as, Probability Proportionate to Sample (PPS). It is also necessary to relate the communication barriers with other 
organizational performance indicators, such as, employee productivity, or performance. Furthermore, to enrich this field of academic research more researches should be conducted rigorously on the communication process of business organizations, especially in the banks where effective communication is a major performance improving factor.

\subsection{Conclusions and recommendations}

This study provides valuable implications for the commercial banks of Bangladesh that have growing interest in attracting and retaining quality employees. The study revealed statistically significant contribution of the components of communication barriers. As it has been shown that among the classified components, component 1 - personal barriers including variables like Local tone, Hot temper, Lack of English knowledge and Opposite sex contribute the most $(22.836 \%$ variance) in creating communication barrier. So it is imperative for banks to undertake effective measures like arranging workshops and training programs to eliminate these barriers. For example, to improve the local tone and use of English banks can arrange workshops or training programs on improving pronunciation and speaking and writing skills both for Bangla and English. Also it is necessary to speak in the language that is understood by the receiver (Gopal, 2004). To control hot temper psychological counseling can be arranged. The sender should first cool down and then begin his communication (Gopal, 2004). Emotional barrier should be controlled consciously and people must take care to keep unnecessary feeling out of business communication (Gopal, 2004). To be comfortable in communication with opposite sex they need to observe their communicating style first respond accordingly. Make observations in their conversation (Kelley, 1996). Discuss these conversational differences at an appropriate time, not when conflict arises. Try to determine if your perceptions are accurate (Kelley, 1996). Personal barriers can be overcome only by making a conscious effort and by training for better communication skills (Gopal, 2004).

Other components - job barriers contribute $18.208 \%$ variance and organizational barriers $15.175 \%$ variance. To improve the communication the job should be designed in such a way that personal life does not interfere in work life such as by establishing family-friendly working policies. And overcoming the barrier of technical words it is necessary to speak in the language that is understood by the receiver (Gopal, 2004). To reduce job monotony, job rotation and job enrichment can be arranged.

The third component- organizational barriers contribute $15.175 \%$ variance. The commercial bank management should emphasize on the policy implications based on these concerned barriers of communication of employees, for example to reduce the barrier of defective technology, sophisticated technology should be used and the employees should be trained with those technologies. To reduce the effect of internal politics on communication system, fair and healthy environment should be ensured. Moreover, to reduce communication barriers one effective method is to foster an ambiance that promotes open flow of communication where employees don't have to feel worried or nervous to communicate with top level or each other.

There is no doubt that an improved communication can lead to higher level of job performance, which in turn will increase job satisfaction and reduce employee turnover that is prevailing in the commercial banks of Bangladesh. Moreover this will help the banks to gain competitive advantage based on skilled human resources. A large number of employees are acting as assets in the commercial banks of Bangladesh. They are playing a significant role for economic growth by contributing their knowledge, skills and efforts. So transforming the workplace proactively using well designed communication system for the incumbents will yield competitive advantage as it will add to the confidence as well as the job satisfaction of the employees. This in turn will inspire them to perform in superior way, leading the banks and their stakeholders to a better future by yielding the expected outcome. 


\section{References:}

Aaker, D. A., \& Georges, S. D. (1990). Marketing research (4 ${ }^{\text {th }}$ ed.). New York: John Wiley and Sons.

Ahmad, S., \& Khanal, D. R. (2007). Services trade in developing Asia: A case study of the banking and insurance sector in Bangladesh. Asia-Pacific Research and Training Network on Trade. Working Paper Series No. 38

Al-Rawas, A., \& Easterbrook, S. (1996). Communication problems in requirements engineering: A field study. Proceedings of the First Westminster Conference on Professional Awareness in Software Engineering, Royal Society, London, 1-2 February.

Bovee, C. L., Thill, J. V., \& Chaturvedi, M. (2008). Business communication today ( $9^{\text {th }}$ ed.). Delhi: Pearson Education.

Braedyn, A. (2010). Gender communication: The impact gender has on effective communication. Suite 101.

Duggirala, M., Rajendran, C., \& Anantharaman, R. N. (2008). Provider-perceived dimensions of total quality management in healthcare. Benchmarking, 15(6), 693-722. $<$ http://dx.doi.org/10.1108/14635770810915904>

Eisenhardt, K. M., \& Bourgeois, L. J. (1988). Politics of strategic decision making in high velocity environments: Toward a midrange theory. Academy of Management Journal, 31, 737-770. $<$ http://dx.doi.org/10.2307/256337>

Fisher, D. (1981). Communication in organizations. New York: West Publishing Co.

Fujun, L., Hutchinson, J., Li, D., \& Bai, C. (2007). An empirical assessment and application of SERVQUAL in mainland China's mobile communications industry. The International Journal of Quality \& Reliability Management, 24(3), 244-262.

Gopal, N. (2004). Business communication: Oral and written. New Delhi: Galgotia Publications Pvt. Ltd.

Grasso, L. P., Golen, S. P., \& Burns, A. (2005). Managerial perceptions of barriers to internal corporate communication within and across hierarchical levels. ABEA Journal, 24.

Hair, J., Black, W., Babin, B., Anderson, R., \& Tatham, R. 2007. Multivariate data analysis (6th ed.). New Jersey: Pearson Education, Inc.

Helen, R., \& Alla, B. (2011). Bank communication processes management.

Islam, M. A., \& Husian, S. M. (2001). Banking in Bangladesh: A Historical Perspective. Journal of Business Studies, 22(2), 309-320.

Khan, A. A., \& Taher, M. A. (2012). Business communication and report writing ( ${ }^{\text {rd }}$ ed.). Dhaka: Abir Publication.

Kumar, R. (2009). Research methodology: A step-by-step guide for beginners (2 ${ }^{\text {nd }}$ ed.). Delhi: Pearson Education.

Lesikar, R. V., Flatley, M. E., Rentz, K., \& Pande, N. (2009). Business communication: Making connections in a digital world $\left(11^{\text {th }}\right.$ ed.). New Delhi: Tata McGraw-Hill Education Private Limited.

Locker, K. O. (2000). Business and administrative communication ( $5^{\text {th }}$ ed.). Boston: Irwin McGraw-Hill.

Malhotra, N. K. (2010). Marketing research: An applied orientation. Boston: Pearson Education.

Pearce, C. G., Figgins, R., \& Golen S. P. (1988). Business communication: Principles and applications $\left(2^{\text {nd }}\right.$ ed.). New York: John Wiley.

Rahman, M. I., Gurung, H. B., \& Saha, S. (2006). Where the job satisfaction of bank employees lies: An analysis of the satisfaction factors in Dhaka city. The Cost and Management Journal of ICMAB, 34(3).

Reinsch, L. (1991). Editorial: what is business communication? The Journal of Business Communication, 28, 305-310. <http://dx.doi.org/10.1177/002194369102800401>

Sherblom, J. (1998). Transforming business communication by building on Forman's translation metaphor. The Journal of Business Communication, 35, 74-86. <http://dx.doi.org/10.1177/002194369803500105>

Siddiqi, K. O. (2010). Interrelations between service quality attributes, customer satisfaction and customer loyalty in the retail banking sector in Bangladesh. International Trade \& Academic Research Conference (ITARC) - London.

Sivadas, E., \& Dwyer, F. R. (2000). An examination of organizational factors influencing new product success in 
internal and alliance based processes. Journal of Marketing, 64, 31-49.

$<$ http://dx.doi.org/10.1509/jmkg.64.1.31.17985>

Sosa, M. E., Eppinger, S. D., Pich, M., McKendrick, D. G., \& Stout, S. K. (2002). Factors that influence technical communication in distributed product development: An empirical study in the telecommunications industry. IEEE Transactions on Engineering Management, 49(1), 45-58. $<$ http://dx.doi.org/10.1109/17.985747>

Timm, P. R., \& Jones, C. G. (1983). Business communication - Getting results. New Jersey: Prentice-Hall. van Riel, C. B. M. (1995). Principles of corporate communication. Hertfordshire: Prentice Hall.

van Ruler, B., \& Lange, R. (2003). Barriers to communication management in the executive suite. Public Relations Review, 29, 145-158. <http://dx.doi.org/10.1016/S0363-8111(03)00017-1> 
Sultana, N., Abdullah, A. M., \& Tabassum, A. 